\title{
Utilização de Subprodutos de Origem Animal em Dietas para Frangos de Corte com Base no Conceito de Proteínas Bruta e Ideal, no Período de 43 a 49 Dias de Idade ${ }^{1}$
}

\author{
Luciana Cardoso Cancherini ${ }^{2}$, Otto Mack Junqueira ${ }^{3}$, Marcelo de Oliveira Andreotti ${ }^{4}$, \\ Maria José Baptista Barbosa ${ }^{5}$, Maria Cristina de Oliveira ${ }^{6}$
}

\begin{abstract}
RESUMO - Foi conduzido um experimento para avaliar a utilização de subprodutos de origem animal em rações para frangos de corte, formuladas com base nas proteínas bruta e ideal no período de 43 a 49 dias de idade. Foram utilizados 600 frangos machos distribuídos em arranjo fatorial 2x2+1, com duas fontes de proteína de origem animal (farinha de vísceras de aves e farinha de sangue bovino), dois conceitos de formulação (proteínas bruta e ideal) e uma ração testemunha à base de milho e de farelo de soja, com quatro repetições cada. As características avaliadas foram ganho de peso, consumo de ração, conversão alimentar, rendimento de carcaça, peito e porcentagem de gordura abdominal. Os melhores ganho em peso e conversão alimentar foram obtidos quando a dieta à base de milho e farelo de soja foi utilizada. As farinhas de vísceras e de sangue e os conceitos de formulação não exerceram influência sobre as características avaliadas.
\end{abstract}

Palavras-chave: farinha de sangue bovina, farinha de vísceras de aves, frangos de corte, proteína ideal

\section{Utilization of Animal By-products in Broilers Diets Based on the Concept of Crude and Ideal Protein in the Period from 43 to 49 Days of Age}

\begin{abstract}
One experiment was conducted to study the utilization of animal by-products in broilers diets based on the concept of crude and ideal protein form 43 to 49 days of age. Sixty hundred Ross male broilers were used in a factorial arrangement 2x2+1 (two animal sources by-products - poultry viscera meal and bovine blood meal - crude and ideal protein) and one basal diet (corn + soybean meal), envolving a total of five treatments with four replications of thirty broilers each. Weight gain, feed intake, feed conversion, carcass and breast yield and the abdominal fat percentage were evaluated. The best weight gain and feed conversion were obtained when birds were fed a corn and soybean meal based diet. The poultry viscera and bovine blood meals and formulation concepts did not influence on evaluated parameters.
\end{abstract}

Key Words: bovine blood meal, poultry viscera meal, broilers, ideal protein

\section{Introdução}

As aves não apresentam alta exigência de proteína bruta, mas precisam de quantidade suficiente para uma reserva de nitrogênio para síntese de aminoácidos não-essenciais. O surgimento do conceito de proteína ideal oferece perspectiva promissora para redução dos níveis de proteína da dieta de frangos de corte, sem efeitos negativos sobre o desempenho ou custos.

Várias pesquisas comprovaram que o excesso de aminoácidos na dieta não contribui para melhorar o desempenho do animal, ou seja, não são utilizados eficientemente. Os aminoácidos em excesso sofrem desaminação e o nitrogênio é excretado como uréia pelos mamíferos ou ácido úrico pelas aves, sendo que este processo reflete em gasto energético para o animal.

Durante muitos anos, as dietas para aves foram formuladas com base no conceito de proteína bruta, o que resultou em dietas com conteúdo de aminoácidos acima do exigido pelos animais. Com o surgimento da produção de aminoácidos sintéticos, as dietas passaram a ser formuladas com menor nível protéico e com níveis de aminoácidos mais próximos das necessidades da ave. Torna-se difícil definir as exigências de aminoácidos para as aves, posto que são influenciadas pela densidade calórica da dieta, pelas condições ambientais, pela densidade populacional, pelo estado sanitário, entre outros. Todavia, uma prática ainda

\footnotetext{
${ }^{1}$ Projeto financiado pela FAPESP - Processo 99/01309-6.

${ }^{2}$ Doutoranda em Zootecnia da FCAV/UNESP, Jaboticabal - SP (lucianac@fcav.unesp.br).

3 Professor do Depto. de Zootecnia da FCAV/UNESP, Jaboticabal - SP.

${ }^{4}$ Professor do Depto. de Zootecnia da UFMS, Campo Grande - MS.

5 Professora do Depto. de Zootecnia da UEM, Maringá -PR.

6 Professora do Depto. de Zootecnia da FESURV, Rio Verde - GO.
} 
comum entre os nutricionistas de aves e suínos é a formulação com base em proteína bruta e aminoácidos totais, sendo que outros nutrientes, como o fósforo e a energia, são calculados em proporções disponíveis, com maior precisão. Segundo Parsons et al. (1992), formular dietas com base em aminoácidos totais significa formular dietas para aves com base em energia bruta.

O conceito de proteína ideal foi definido, primeiramente por Mitchell (1964), como uma mistura de aminoácidos ou proteína cuja composição atende às exigências dos animais para os processos de mantença e crescimento. De acordo com Parsons \& Baker (1994), proteína ideal é uma mistura de aminoácidos ou de proteínas com total disponibilidade de digestão e metabolismo, capaz de fornecer sem excessos nem deficiências as necessidades absolutas de todos os aminoácidos requeridos para manutenção e produção da ave, no sentido de favorecer a deposição protéica com máxima eficiência. Segundo Penz Jr. (1996), para ser ideal, a proteína ou a combinação não deve possuir aminoácidos em excesso. Assim, os aminoácidos devem estar presentes na dieta exatamente nos níveis exigidos para a mantença e máxima deposição protéica.

Certamente, não existem dúvidas de que as proporções de aminoácidos devem ser expressas em termos de digestíveis, em vez de totais, e, caso sejam incluídos outros alimentos além do milho e da soja, é importante considerar as diferenças na digestibilidade desses alimentos e, conseqüentemente, elaborar a formulação com base no conteúdo de aminoácidos digestíveis.

Rostagno et al. (1995), avaliando o desempenho de frangos de corte alimentados com dietas formuladas com aminoácidos totais ou digestíveis, observaram melhor conversão alimentar e maior peso corporal para aves alimentadas com dietas formuladas à base de aminoácidos digestíveis. Em outro experimento, Parsons (1999) mostrou claramente a superioridade ao serem formuladas dietas de frangos de corte conforme suas exigências em aminoácidos digestíveis, em comparação à formulação com base em aminoácidos totais, quando se disponibilizou farinha de carne e ossos de boa ou má qualidade nutricional.

Objetivou-se, com este trabalho, avaliar a utilização dos subprodutos de origem animal (farinha de vísceras de ave e farinha de sangue bovino), para frangos de corte, em dietas formuladas com base no conceito de proteínas bruta e ideal.

R. Bras. Zootec., v.33, n.6, p.2060-2065, 2004 (Supl. 2)

\section{Material e Métodos}

O experimento foi conduzido no Setor de Avicultura da Faculdade de Ciências Agrárias e Veterinárias - UNESP/Jaboticabal. Foram utilizados 600 frangos machos de 43 dias de idade, da linhagem Ross, com peso inicial médio 2.400 g.

O delineamento experimental foi inteiramente casualizado em arranjo fatorial 2 x $2+1$, com dois conceitos de formulação de rações (proteínas bruta e ideal) e dois subprodutos de origem animal (farinha de vísceras de aves e farinha de sangue bovina) e uma ração controle à base de milho e de farelo de soja (MFS), formuladas com base na proteína bruta, totalizando cinco tratamentos e quatro repetições de 30 aves cada.

As aves até o período experimental foram alimentadas com dietas à base de milho e de farelo de soja (MFS). Foi fornecida ração e água à vontade e as aves foram manejadas convencionalmente. As rações utilizadas foram formuladas com base na proteína bruta (PB) ou proteína ideal (PI) e constituídas de subprodutos de origem animal, farinha de vísceras de aves (FVA) e farinha de sangue bovina (FSB), com o nível de inclusão de 6\%. Os tratamentos (T) foram os seguintes: $T_{1}$ - MFS com base na $\mathrm{PB}$ (ração testemunha); $\mathrm{T}_{2}$ - MFS + FVA com base na PB; $\mathrm{T}_{3}$ - MFS + FVA com base na PI; $\mathrm{T}_{4}-\mathrm{MFS}+\mathrm{FSB}$ com base na $\mathrm{PB}$ e $\mathrm{T}_{5}-\mathrm{MFS}+\mathrm{FSB}$ com base na PI.

As rações experimentais foram formuladas segundo as recomendações nutricionais do NRC (1994) (proteína bruta e aminoácidos totais) e segundo Rostagno et al. (1996) (aminoácidos digestíveis) (Tabela 1).

Ao final do período experimental (49 dias de idade), após as pesagens, foram separadas três aves por unidade experimental, utilizando como critério de escolha os frangos que apresentaram o peso corporal médio da respectiva parcela (5\% acima e abaixo da média).

As aves foram abatidas por sangria na artéria jugular após jejum de seis horas. Após o sangramento e a depenação, as aves foram evisceradas e as carcaças (sem cabeça+pescoço, pé e gordura abdominal), pesadas em balança digital. Assim que as aves foram evisceradas, procedeu-se à retirada da gordura abdominal, que foi pesada.

Na determinação do rendimento de carcaça, foi considerado o peso da carcaça limpa e eviscerada (sem cabeça+pescoço, pé e gordura abdominal), em relação ao peso vivo após jejum, obtido antes do abate. 
Tabela 1 - Composição centesimal das dietas experimentais

Table 1 - Percentage composition of the experimental diets

\begin{tabular}{|c|c|c|c|c|c|}
\hline \multirow[t]{3}{*}{$\begin{array}{l}\text { Ingredientes (\%) } \\
\text { Ingredients (\%) }\end{array}$} & \multirow[t]{3}{*}{$\begin{array}{l}\text { Milho+farelo soja } \\
\text { Corn + soybean meal }\end{array}$} & \multicolumn{2}{|c|}{$\begin{array}{l}\text { Farinha de vísceras } \\
\text { Poultry viscera meal }\end{array}$} & \multicolumn{2}{|c|}{$\begin{array}{c}\text { Farinha de sangue } \\
\text { Blood meal }\end{array}$} \\
\hline & & PB & $\mathrm{PI}^{2}$ & PB & $\mathrm{PI}^{2}$ \\
\hline & & $C P$ & $I P$ & $C P$ & $I P$ \\
\hline Milho (Corn) & 65,33 & 70,12 & 66,48 & 71,65 & 75,52 \\
\hline Farelo de soja (Soybean meal) & 27,28 & 19,02 & 22,05 & 15,46 & 12,13 \\
\hline Óleo de soja (Soybean oil) & 3,80 & 1,70 & 2,29 & 3,12 & 2,42 \\
\hline Fosfato bicálcico (Dicalcium phosphate) & 1,60 & 1,40 & 1,35 & 1,87 & 1,94 \\
\hline Calcário calcítico (Limestone) & 1,10 & 0,94 & 0,95 & 1,00 & 0,99 \\
\hline Sal comum (Salt) & 0,34 & 0,31 & 0,31 & 0,32 & 0,33 \\
\hline Supl. mineral + vitamínico ${ }^{1}$ (Min/vit. supplement) & 0,50 & 0,50 & 0,50 & 0,50 & 0,50 \\
\hline DL-metionina 99\% (DL-methionine) & 0,05 & 0,01 & 0,07 & 0,08 & 0,17 \\
\hline L-lisina HCl 78\% (Lysine chloride 78\%) & - & - & - & - & - \\
\hline Farinha de vísceras (Poultry viscera meal) & - & 6,00 & 6,00 & - & - \\
\hline Farinha de sangue (Blood meal) & - & - & - & 6,00 & 6,00 \\
\hline \multirow[t]{2}{*}{ Total } & 100,00 & 100,00 & 100,00 & 100,00 & 100,00 \\
\hline & \multicolumn{5}{|c|}{$\begin{array}{l}\text { Composição estimada } \\
\text { Estimated composition }\end{array}$} \\
\hline $\mathrm{EM}(\mathrm{kcal} / \mathrm{kg})(M E)$ & 3.200 & 3.200 & 3.200 & 3.200 & 3.200 \\
\hline $\mathrm{PB}(\%)(C P)$ & 18,00 & 18,00 & 19,00 & 18,00 & 16,80 \\
\hline Lisina $(\%)($ Lysine $)$ & 0,914 & 0,850 & 0,926 & 1,012 & 0,927 \\
\hline Metionina+cistina (\%) (Methionine + cystine) & 0,823 & 0,749 & 0,818 & 0,894 & 0,818 \\
\hline Lisina digestível (\%) (Digestible lysine) & 0,650 & 0,650 & 0,739 & 0,650 & 0,712 \\
\hline Metionina+cistina digestível (\%) & 0,583 & 0,561 & 0,646 & 0,580 & 0,646 \\
\hline \multicolumn{6}{|l|}{ Digestible Methionine + cystine (\%) } \\
\hline Fósforo disponível (\%) (Available P) & 0,400 & 0,507 & 0,501 & 0,447 & 0,457 \\
\hline Cálcio (\%) (Calcium) & 0,900 & 0,900 & 0,900 & 0,900 & 0,900 \\
\hline \multicolumn{6}{|c|}{ 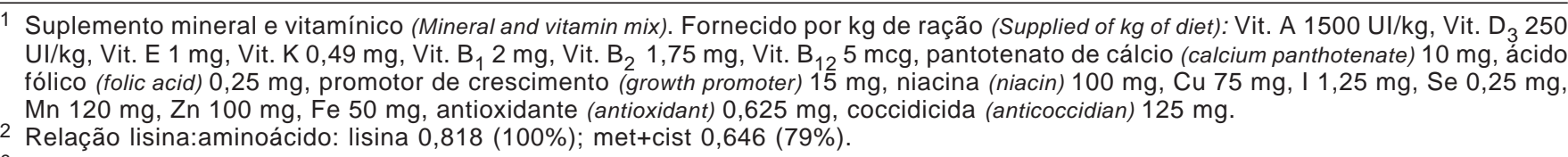 } \\
\hline
\end{tabular}

Considerou-se gordura abdominal aquela depositada na região abdominal, próxima à Bursa de Fabricius, e gordura aderida, à moela e ao proventrículo.

O rendimento do peito e a porcentagem da gordura abdominal foram calculados em relação ao peso da carcaça eviscerada.

Os dados obtidos foram submetidos à análise estatística, utilizando o programa “ESTAT”. Em caso de significância estatística, as médias foram comparadas pelo teste Tukey (5\%).

\section{Resultados e Discussão}

Apenas a conversão alimentar apresentou interação estatisticamente significativa $(P<0,05)$ entre fontes de proteína de origem animal e conceitos de formulação (Tabela 2). Portanto, existe depen- dência entre os fatores, não sendo possível estudar os efeitos principais isoladamente, exceto para consumo de ração e ganho de peso. Nestas condições, procedeu-se ao estudo dos efeitos principais de cada fator isoladamente, mas observa-se que também não foram significativos $(\mathrm{P}>0,05)$.

Observa-se que as aves alimentadas com farinha de sangue formuladas com base na PB apresentaram melhor conversão alimentar em relação àquelas que receberam farinha de sangue formuladas com base no conceito de PI, sendo esta diferença estatisticamente significativa $(\mathrm{P}<0,05)$ (Tabela 2$)$. Contudo, observando-se os dados das dietas formuladas no conceito $\mathrm{PB}$, verifica-se que as aves alimentadas com farinha de sangue nas dietas apresentaram melhor $(\mathrm{P}<0,05)$ conversão alimentar significativamente.

Os subprodutos de origem animal (FVA e FSB) não influenciaram o ganho de peso e o consumo de 
ração (Tabela 2). Com relação aos conceitos de formulação (PB e PI), o consumo de ração e o ganho de peso não foram estatisticamente diferentes $(\mathrm{P}>0,05)$, o que pode ser atribuído ao bom balanceamento de aminoácidos das dietas. Segundo Gonzales (2002), o controle do consumo não é decorrente somente da quantidade de proteína bruta, mas também de sua qualidade, isto é, do balanceamento entre os aminoácidos. Os resultados obtidos nesta pesquisa discordam dos apresentados por Bregendahl et al. (2002), que observaram maior consumo de ração em frangos machos recebendo baixo nível de proteína bruta.

Embora não tenha ocorrido diferença significativa, os resultados para ganho de peso (Tabela 2) indicam que as aves alimentadas com ração à base de milho e de farelo de soja, apesar de apresentarem ganho de peso superior aos demais tratamentos, não foram significativamente diferentes. Este fato pode ser atribuído ao CV (8,48\%), pois as aves alimentadas com a ração contendo apenas milho e farelo de soja ganharam $18 \%$ a mais em peso, quando comparadas àquelas que receberam a farinha de vísceras dentro do conceito de proteína bruta.

Analisando o efeito significativo testemunha $\mathrm{x}$ fatorial para conversão alimentar, pelo teste de comparação de médias, observa-se melhora na conversão para a testemunha (milho + farelo de soja), que foi estatisticamente diferente $(\mathrm{P}<0,05)$ apenas para as aves que receberam ração contendo farinha de vísceras formuladas nos dois conceitos (PB e PI) e farinha de sangue formulada pelo conceito da PI (Tabela 3). Apesar da não-significância, a dieta formulada com base na proteína ideal na presença de farinha de vísceras resultou em melhor conversão alimentar que a ração formulada com proteína bruta, corroborando os resultados obtidos por Araújo (2001) e Mendonza et al. (2001), que observaram melhor desempenho de frangos recebendo dietas formuladas com o conceito de proteína ideal.

As dietas formuladas com farinha de sangue com base no conceito de proteína ideal resultaram em

Tabela 2 - Consumo de ração, ganho de peso e conversão alimentar de frangos de corte, no período de 43 a 49 dias de idade

Table 2 - Feed intake, weight gain and feed conversion of broilers in the period from 43 to 49 days of age

\begin{tabular}{|c|c|c|c|c|c|}
\hline \multirow[t]{2}{*}{$\begin{array}{l}\text { Subprodutos } \\
\text { By-products }\end{array}$} & \multicolumn{2}{|c|}{$\begin{array}{l}\text { Proteína } \\
\text { Protein }\end{array}$} & \multirow[t]{2}{*}{$\begin{array}{l}\text { Média } \\
\text { Mean }\end{array}$} & \multirow[t]{2}{*}{$\begin{array}{l}\text { Testemunha } \\
\text { Control }\end{array}$} & \multirow[t]{2}{*}{ CV (\%) } \\
\hline & $\begin{array}{l}\text { Bruta } \\
\text { Crude }\end{array}$ & $\begin{array}{l}\text { Ideal } \\
\text { Ideal }\end{array}$ & & & \\
\hline $\begin{array}{l}\text { Consumo de ração }(\mathrm{g}) \\
\text { Feed intake }\end{array}$ & & & & & 5,91 \\
\hline $\begin{array}{l}\text { Farinha de vísceras de aves } \\
\text { Poultry viscera meal }\end{array}$ & 1390 & 1380 & $1385^{a}$ & & \\
\hline $\begin{array}{l}\text { Farinha de sangue bovina } \\
\text { Blood meal }\end{array}$ & 1400 & 1470 & $1435^{a}$ & & \\
\hline $\begin{array}{l}\text { Média } \\
\text { Mean }\end{array}$ & $1395^{\mathrm{a}}$ & $1425^{\mathrm{a}}$ & & 1400 & \\
\hline $\begin{array}{l}\text { Ganho de peso (g) } \\
\text { Weight gain }\end{array}$ & & & & & 8,48 \\
\hline $\begin{array}{l}\text { Farinha de vísceras } \\
\text { Poultry viscera meal }\end{array}$ & 470 & 480 & $475^{\mathrm{a}}$ & & \\
\hline $\begin{array}{l}\text { Farinha de sangue bovina } \\
\text { Bovine blood meal }\end{array}$ & 520 & 500 & $510^{\mathrm{a}}$ & & \\
\hline $\begin{array}{l}\text { Média } \\
\text { Mean }\end{array}$ & $495^{a}$ & $490^{\mathrm{a}}$ & & 555 & \\
\hline $\begin{array}{l}\text { Conversão alimentar } \\
\text { Feed conversion }\end{array}$ & & & & & 5,28 \\
\hline $\begin{array}{l}\text { Farinha de vísceras } \\
\text { Poultry viscera meal }\end{array}$ & $2,94^{\mathrm{aA}}$ & $2,89^{\mathrm{aA}}$ & 2,92 & & \\
\hline $\begin{array}{l}\text { Farinha de sangue bovina } \\
\text { Bovine blood meal }\end{array}$ & $2,70^{\mathrm{bB}}$ & $2,96^{\mathrm{aA}}$ & 2,83 & & \\
\hline $\begin{array}{l}\text { Média } \\
\text { Mean }\end{array}$ & 2,82 & 2,93 & & 2,54 & \\
\hline
\end{tabular}

Letras minúsculas distintas na linha e maiúsculas na coluna diferem $(p<0,05)$ pelo teste Tukey.

Small and different letters within the row and capital letters within the column differ $(p<.05)$ by Tukey test.

R. Bras. Zootec., v.33, n.6, p.2060-2065, 2004 (Supl. 2) 
piores conversões em relação às formuladas pelo conceito de proteína bruta, o que era não esperado, pois, segundo Sakomura \& Silva (1998), dietas formuladas com proteína ideal atenderiam mais eficientemente aos requerimentos de aminoácidos em relação às formuladas com base na concentração total de aminoácidos. Entretanto, isto não foi possível, provavelmente em razão da menor digestibilidade dos aminoácidos contidos na farinha de sangue.

A baixa digestibilidade de aminoácidos em um ingrediente pode estar relacionada com a presença de fatores antinutricionais, sub ou superprocessamento, propriedades físicas ou químicas ou presença de altos níveis de fibra. Os efeitos de processamento, como alta de temperatura ou pressão, podem contribuir significativamente para o decréscimo da disponibilidade de aminoácidos, principalmente em ingredientes como farinhas de origem animal (Parsons et al., 1992). Os resultados obtidos por Wang et al. (1995) corroboram os verificados por Parsons et al. (1992), que, avaliando a qualidade da proteína de subprodutos de origem animal, determinaram a digestibilidade da farinha de carne e ossos e da farinha de vísceras de diferentes empresas que processavam as farinhas com temperaturas altas e baixas e observaram a influência da temperatura na digestibilidade dos aminoácidos nas farinhas.

Os resultados para rendimento de carcaça, peito e gordura abdominal aos 49 dias de idade são apresentados na Tabela 4 . Não foram verificadas interações entre fontes de proteína de origem animal e conceitos de formulação; portanto, não existe dependência

Tabela 3 - Conversão alimentar de frangos de corte, no período de 43 a 49 dias de idade

Table 3 - Feed conversion of broilers in the period from 43 to 49 days of age

\begin{tabular}{lccccc}
\hline $\begin{array}{l}\text { Características } \\
\text { Characteristics }\end{array}$ & \multicolumn{3}{c}{$\begin{array}{c}\text { Tratamentos } \\
\text { Treatments }\end{array}$} \\
\cline { 2 - 6 } & $\mathrm{M}+\mathrm{FS}$ & FVA $(\mathrm{PB})$ & FVA(PI) & FSB (PB) & FSB (PI) \\
& $C+S M$ & $P V M(C P)$ & $P V M(I P)$ & $B M(C P)$ & $B M(I P)$ \\
\hline $\begin{array}{l}\text { Conversão alimentar } \\
\text { Feed conversion }\end{array}$ & $2,54^{\mathrm{b}}$ & $2,94^{\mathrm{a}}$ & $2,89^{\mathrm{a}}$ & $2,70^{\mathrm{ab}}$ & $2,96^{\mathrm{a}}$ \\
\hline
\end{tabular}

Médias dentro da mesma linha seguidas por letras iguais não diferem $(p>0,05)$ pelo teste Tukey.

Means within the same row followed by the same letters are not different $(p>.05)$ by Tukey test.

$\mathrm{M}=$ milho, FS = farelo de soja, FVA = farinha de vísceras, FSB = farinha de sangue, PB = proteína bruta e PI = proteína ideal.

$C=$ corn, $S M=$ soybean meal, $P V M=$ poultry viscera meal, $B M=$ blood meal,$P B=$ protein crude and $P I=$ protein ideal .

Tabela 4 - Rendimento de carcaça e de peito e porcentagem de gordura abdominal de frangos de corte aos 49 dias de idade

Table 4 - Carcass and breast yield and abdominal fat percentage at broilers in 49 days of age

\begin{tabular}{|c|c|c|c|c|c|}
\hline \multirow[t]{2}{*}{$\begin{array}{l}\text { Subprodutos } \\
\text { By-products }\end{array}$} & \multicolumn{2}{|c|}{$\begin{array}{l}\text { Proteína } \\
\text { Protein }\end{array}$} & \multirow[t]{2}{*}{$\begin{array}{l}\text { Média } \\
\text { Mean }\end{array}$} & \multirow[t]{2}{*}{$\begin{array}{l}\text { Testemunha } \\
\text { Control }\end{array}$} & \multirow[t]{2}{*}{ CV $(\%)$} \\
\hline & $\begin{array}{l}\text { Bruta } \\
\text { Crude }\end{array}$ & $\begin{array}{l}\text { Ideal } \\
\text { Ideal }\end{array}$ & & & \\
\hline Rendimento de carcaça (\%) (Carcass yield) & & & & & 12,44 \\
\hline Farinha de vísceras de aves (Poultry viscera meal) & 68,4 & 70,0 & $69,2^{\mathrm{a}}$ & & \\
\hline Farinha de sangue bovina (Bovine blood meal) & 68,6 & 68,8 & $68,7^{\mathrm{a}}$ & & \\
\hline Média (Mean) & $68,5^{\mathrm{a}}$ & $69,4^{\mathrm{a}}$ & & 68,6 & \\
\hline Rendimento de peito (\%) (Breast yield) & & & & & 5,04 \\
\hline Farinha de vísceras (Poultry viscera meal) & 33,6 & 34,2 & $33,9^{\mathrm{a}}$ & & \\
\hline Farinha de sangue bovina (Bovine blood meal) & 33,0 & 33,8 & $33,4^{\mathrm{a}}$ & & \\
\hline Média (Mean) & $33,3^{\mathrm{a}}$ & $34,0^{\mathrm{a}}$ & & 33,4 & \\
\hline Gordura abdominal (\%) (Abdominal fat) & & & & & 18,97 \\
\hline Farinha de vísceras (Poultry viscera meal) & 3,1 & 3,0 & $3,0^{\mathrm{a}}$ & & \\
\hline Farinha de sangue bovina (Bovine blood meal) & 3,3 & 3,0 & $3,2^{\mathrm{a}}$ & & \\
\hline Média (Mean) & $3,2^{\mathrm{a}}$ & $3,0^{\mathrm{a}}$ & & 2,8 & \\
\hline
\end{tabular}

Letras distintas na linha diferem $(p<0,05)$ pelo teste Tukey.

Different letters within the row differ $(p<.05)$ by Tukey test.

R. Bras. Zootec., v.33, n.6, p.2060-2065, 2004 (Supl. 2) 
entre os fatores (proteína e subprodutos) que atuam independentemente. Nestas condições, procedeu-se ao estudo dos efeitos principais de cada fator isoladamente, mas observa-se que também não foram significativos $(\mathrm{P}>0,05)$.

Apesar da não-significância, os resultados de rendimento de carcaça e de peito (Tabela 4) indicam que as aves alimentadas com a ração formulada pelo conceito de proteína ideal, apresentaram melhor rendimento de carcaça e de peito, quando comparadas àquelas que receberam ração formulada pelo conceito tradicional (proteína bruta). Estes resultados confirmam os obtidos por Araújo (2001), que observaram efeito significativo no rendimento de carcaça de frangos de corte de 43 a 56 dias de idade, submetidos a dietas com níveis protéicos crescentes, formuladas com base em aminoácidos digestíveis e aminoácidos totais.

Embora as aves alimentadas com rações formuladas pelo conceito de proteína bruta tenham apresentado maior porcentagem de gordura abdominal, esta diferença não foi significativa, possivelmente em decorrência do alto coeficiente de variação (18,97\%), corroborando os resultados obtidos por Dari \& Penz Jr. (1996) e Araújo (2001).

\section{Conclusões}

Rações contendo farinha de vísceras podem ser formuladas com base nas proteínas bruta ou ideal.

Rações contendo farinha de sangue, quando formuladas com base na proteína bruta, resultam em melhor desempenho para as aves de 43 a 49 dias de idade.

\section{Literatura Citada}

ARAÚJO, L.F. Estudos de diferentes critérios de formulação de rações, com base em perfis de aminoácidos totais e digestíveis para frangos de corte. Jaboticabal: Universidade Estadual Paulista, 2001. 123p. Tese (Doutorado em Zootecnia) - Universidade Estadual Paulista, 2001.

BREGENDAHL, K.; SELL, J.L.; ZIMMERMAN, D.R. Effect of low-protein diets on growth performance and body composition of broiler chicks. Poultry Science, v.81, n.8, p.1156-1167, 2002.

DARI, R.L.; PENZ JR., A.M. The use of digestible amino acid and ideal protein concept in diet forumlation for broilers. In: POULTRY SCIENCE ASSOCIATION 85 TH ANNUAL MEETING, 1996, Louisville. Anais... Louisville: Poultry Science Association, 1996. p.67.
ESTAT. Sistema para análise estatística. Departamento de exatas. FCAV/UNESP. Jaboticabal-SP versão 4.03.

GONZALES, E. Ingestão de alimentos: mecanismos regulatórios. In: MACARI, M.; FURLAN, R.L.; GONZALES, E. (Eds.). Fisiologia aviária: aplicada a frangos de corte. 2.ed. Jaboticabal: FUNEP, 2002. p.187-199.

MENDONZA, M.O.B.; COSTA, P.T.C.; KATZER, L.H. et al. Desempenho de frangos de corte, sexados, submetidos a dietas formuladas pelos conceitos de proteína bruta versus proteína ideal. Ciência Rural, v.31, p.111-115, 2001.

MITCHELL, H.F. Comparative nutrition of man and domestic animals. New York: Academic Press, 1964. p.567-647.

NATIONAL RESEARCH COUNCIL - NRC. Nutrients requeriments of poultry. 9.ed. Washington, D.C.: National Academy Press, 1994. 155p.

PARSONS, C.M.; BAKER, D.H. The concept and usage of ideal proteins in the feeding of nonruminantes. In: SIMPÓSIO INTERNACIONAL DE PRODUÇÃO DE NÃO-RUMINANTES, 1994, Maringá. Anais... Maringá: Universidade Estadual do Paraná, 1994. p.119-128.

PARSONS, C.M.; HASHIMOTO, K.; WEDEKIND, K.J. et al. Effect of overprocessing on availability of amino acids and energy in soybean meal. Poultry Science, v.71, p.133-140, 1992.

PARSONS, C. M. Protein quality and amino acid digestibility of animal protein meals. In: MULTI-STATE POULTRY MEETING, 1999, Arkansas. Proceedings... Arkansas: 1999. p.35-42.

PENZ JR., A.M. O uso do conceito de proteína ideal para monogátricos. In: CONGRESSO INTERNACIONAL DE ZOOTECNIA, 1996, Porto Alegre. Anais ... Porto Alegre: Universidade Federal do Rio Grande do Sul, 1996. p.71-85.

ROSTAGNO, H.S.; BARBARINO JR., P; BARBOZA, W. A. Exigências nutricionais das aves determinadas no Brasil. In: SIMPÓSIO INTERNACIONAL SOBRE EXIGÊNCIAS NUTRICIONAIS DE AVES E SUÍNOS, 1996, Viçosa, MG. Anais...Viçosa, 1996. p.326-88.

ROSTAGNO, H.S.; PUPA, J.M.R.; PACK, M.J. Diet formulation for broilers based on total versus digestible amino acids. Journal of Applied Poultry Research, v.64, p.119-126, 1995.

SAKOMURA, N.K.; SILVA, R. Conceitos aplicáveis à nutrição de não ruminantes. Cadernos Técnicos da Escola de Veterinária da UFMG, v.22, p.125-46, 1998.

WANG, X.; ZHANG, Y.; PARSONS, C.M. Evaluation of protein quality of meat and bone meals and poultry bypoultry meals. Poultry Science, v.74 (Supp. 1), p.121, 1995. (Abstract 363) 